\title{
Exploring the Cooling Process for Residual Stress Reduction in Dissimilar Welds
}

\author{
$\mathrm{CO}_{2}$ cooling is found to be an effective technique for eliminating \\ stresses in gas tungsten arc welding similar and dissimilar metals
}

BY H. EISAZADEH, E. A. PAYZANT, P. A. CORNWELL, J. R. BUNN, AND D. K. AIDUN

\begin{abstract}
Dissimilar metal welds are currently used in various industry applications; however, a significant number of failures have been reported in these joints due to the existence of large tensile residual stresses induced by arc welding processes. Hence, it is crucial to reduce or eliminate such residual stresses in dissimilar metal welds. Recently, modern techniques such as $\mathrm{CO}_{2}$ rapid cooling have received attention by scholars to reduce residual stress in similar metal welds. Nevertheless, the effectivity of this technique has not been explored in dissimilar metal welds. In this paper, the impact of in-situ rapid local cooling in dissimilar metal welds is studied experimentally. The residual stresses of $\mathrm{CO}_{2}$-cooled welds were measured using the neutron diffraction technique. The effect of rapid cooling on the microstructure of the weld and heat-affected zones were examined. It is shown that for certain cases, in-situ rapid cooling during the arc welding process can minimize tensile residual stresses in dissimilar metal welds.
\end{abstract}

\section{KEYWORDS}

- Residual Stress Reduction • Dissimilar Metal Welds - Rapid Cooling

\section{Introduction}

Residual stress (RS) induced by dissimilar metal welds (DMW) is undesirable since it contributes to premature failures in welded structures. Hence, reducing RS in DMW is of primary concern. A wide variety of techniques are introduced for the reduction or modification of residual stress distributions in similar metal welds, such as heat treatment and peening processes. These are the common (conventional) techniques used nowadays, but their effectiveness on DMW is still questionable (Ref. 1). In addition, not only do such methods demand expensive equipment and energy, but some of them, such as the heat treatment method, are not applicable when a large welded structure is the case for RS reduction.

Recently, two modern methods, so-called in-situ rapid cooling (Ref. 2) and global mechanical tensioning (GMT) (Refs. 3, 4), were designed to work against the formation of RS during the welding process. These methods have received significant attention over the past two decades because they are more economical and effective compared to the conventional methods. Particularly, the in-situ cooling method sounds more promising than GMT because of its easy adaptation to industrial applications.

The RS reduction in the in-situ cooling method, as the name suggests, can be achieved through modifying the thermal field induced via welding by applying an external cooling source. This method was introduced and implemented by Guan et al. (Ref. 5), and was later named dynamically controlled low stress non-distortion (DC-LSND) welding, where an intense cooling source is applied behind the weld pool (WP). This cooling source induces thermal tensioning near the weld zone (WZ) and reverses the incompatible plastic strain that occurs during the heating stage. The method was also applied by others, Li et al. (Refs. 2, 6), to mitigate $\mathrm{RS}$ and distortion. Both their experimental and numerical outcomes indicated that the RS along the longitudinal direction was reduced by $50 \%$. Moreover, the welding distortion was entirely eliminated.

In their attempt to improve $\mathrm{RS}$ reduction in the welding process, van der Aa et al. (Ref. 7) found that the cooling source has to be tuned to generate intense cooling power and be located as close to the WP as possible.

Through numerical modeling, Richards et al. tested the DC-LSND method in friction stir welding (FSW) of AA 2024T3 plates. Richards et al. also concluded that the location of the cooling source has a great impact on the amount of reduced RS (Ref. 8).

Over the last decade, the DC-LSND or $\mathrm{CO}_{2}$ cooling method has been employed to reduce and eliminate RS and distortions in welding processes (Refs. 9-11). However, at present, the potential benefits of this technique have not been explored on DMWs, where mixture of dissimilar metals makes a fresh composition, and this consequently leads to metal phase transformation.

This study focuses on the experimental implementation of the $\mathrm{CO}_{2}$ cooling method for gas tungsten arc welding (GTAW) of similar and DMWs. The RS distributions of in- 


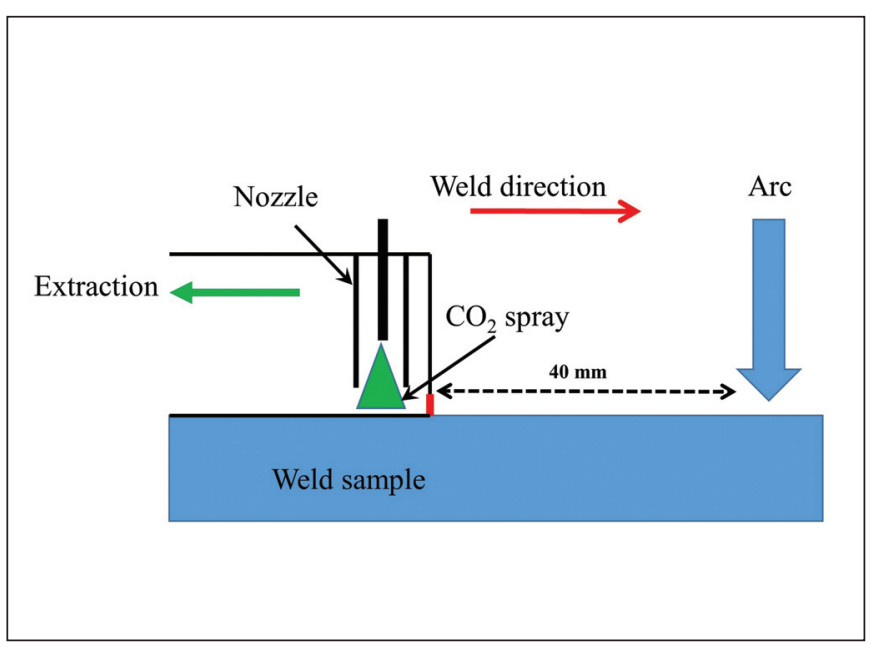

Fig. 1 - Schematic of $\mathrm{CO}_{2}$ welding.

situ rapidly cooled welds (using $\mathrm{CO}_{2}$ ) were investigated using the neutron diffraction (ND) technique. Distortion in 304304 and 1018-1018 similar welds, and their dissimilar metal welds (304-1018), were measured and compared with their corresponding $\mathrm{CO}_{2}$-cooled welds. Microhardness and microstructure changes were also evaluated to explore the effect of the in-situ rapid cooling method at the microstructure level.

\section{Experimental Method}

\section{$\mathrm{CO}_{2}$ Cooling (DC-LSND)}

The technology developed by Li et al. (Ref. 6) was used in this study to reduce the RS and distortion induced by the arc welding process. The schematic used for this method is shown in Fig. 1. In this method, a $\mathrm{CO}_{2}$ cooling source is employed during the GTAW process, which is located $40 \mathrm{~mm}$ behind the welding torch. As the welding torch travels along the weld path (shown by the red arrow), the cooling nozzle travels at the same velocity along with the welding torch while spraying the coolant on the surface of the hot metal behind the WP.

It is necessary that the cooling source behind the welding torch meets essential requirements. The first important key is that it must be capable of cooling the hot region behind the WP fast with a high cooling rate. The second key is that the cooling source needs to be applied to a relatively small area behind the torch to provide a typical temperature distribution - Fig. 2B. Additionally, it is crucial that the cooling source does not interfere with the flow of the shielding gas and the arc, otherwise the arc will become unstable.

As shown in Fig. 2, the highest temperature at the center of the heat sources was approximately the same in both conventional and $\mathrm{CO}_{2}$ welding processes. However, the temperature behind the heat source for the case of $\mathrm{CO}_{2}$ did not drop smoothly in the same pattern as the conventional welding process, as shown by arrows in Fig. $2 \mathrm{~A}$ and B, respectively. Figure $2 \mathrm{~B}$ shows that a sharp temperature drop occurred behind the peak temperature for the $\mathrm{CO}_{2}$ case. The steepness is dependent on the power of the $\mathrm{CO}_{2}$ cooling source.

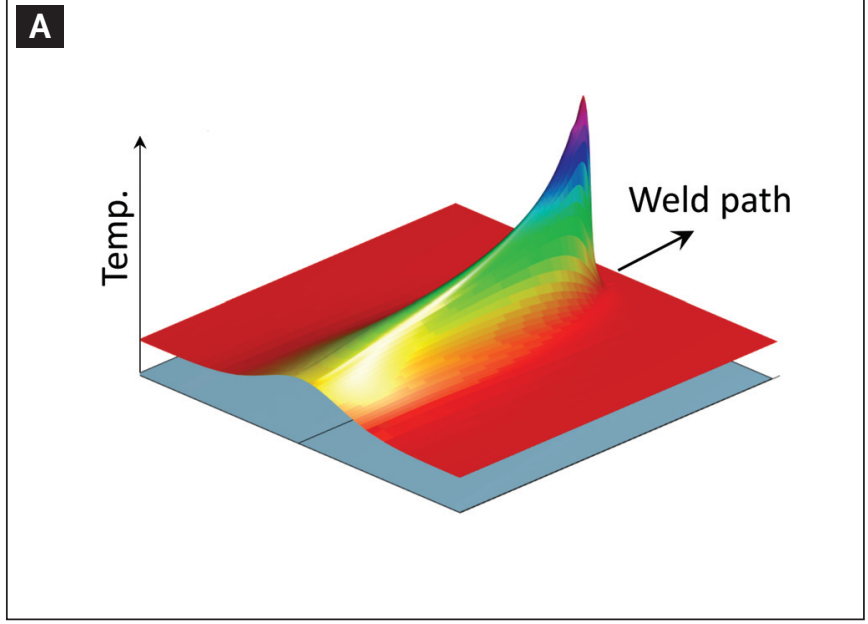

B

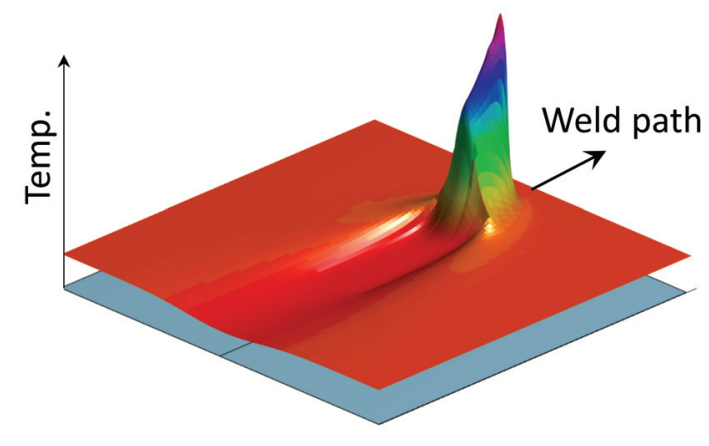

Fig. 2 - Typical temperature distribution: A - Conventional GTAW; $\mathrm{B}-\mathrm{CO}_{2}$ GTAW.

The generated power can be quantified by the uniform convective cooling heat flux, $q_{\text {cooling. }}$. The heat flux $\left(q_{\text {cooling }}\right)$ between a hot plate at temperature, $T$, and the cooling source can be described by Newton's law of cooling:

$$
q_{\text {cooling }}=h_{\text {cooling }} .\left(T-T_{\text {cooling }}\right)
$$

where the interfacial heat transfer $\left(h_{\text {cooling }}\right)$ and the cooling source temperature $\left(T_{\text {cooling }}\right)$ are two variables associated with the cooling source characteristics. Based on Equation 1 , the most effective coolant for the $\mathrm{CO}_{2}$ cooling method, in terms of cooling source strength, should have a large heat transfer coefficient $(h)$, while having a low temperature $\left(T_{\text {cooling }}\right)$. Some of the existing coolants are liquid argon, liquid $\mathrm{CO}_{2}$, and liquid nitrogen. Among these coolants, liquid $\mathrm{CO}_{2}$ is very notable and prominent because of its substantial latent heat during phase change. Since the phase change of liquid $\mathrm{CO}_{2}$ takes place at atmospheric pressure, the cooling power can be significantly high. Normally, the $\mathrm{CO}_{2}$ is filled in tanks as a liquid at $-18^{\circ} \mathrm{C}$ and 18 bar pressure. While spraying this liquid out into one bar pressure (atmospheric pressure), it turns into dry ice with a temperature around $-78^{\circ} \mathrm{C}$. Such low temperature makes the $\mathrm{CO}_{2}$ one of the best coolants and cleaning agents for the $\mathrm{CO}_{2}$ cooling method. 


\section{A}

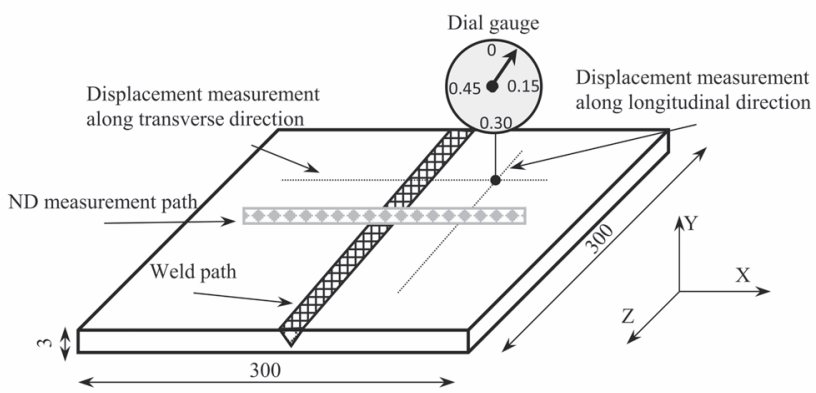

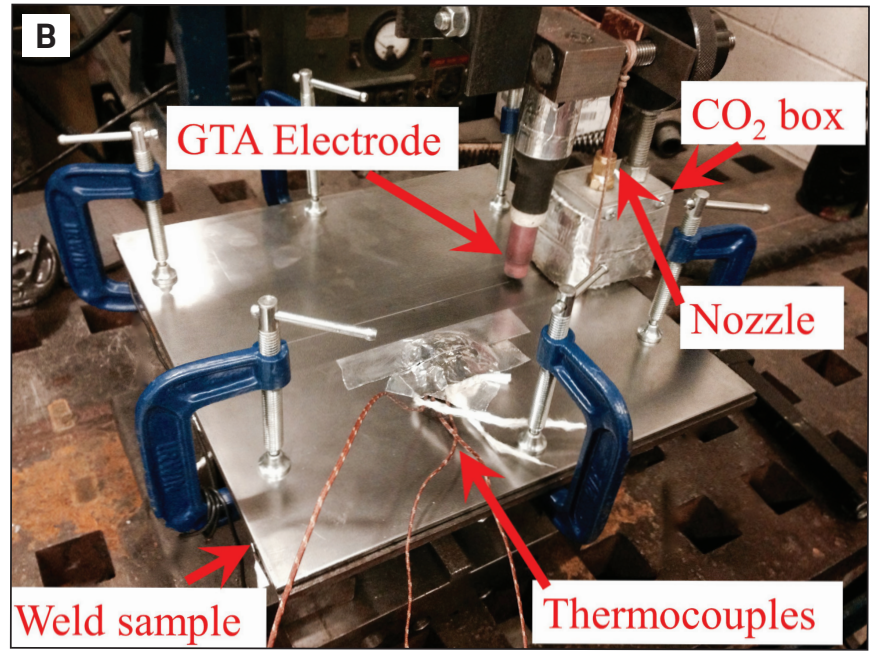

Fig. 3-A - Dimensions and measurement directions of the specimen (dimensions are in mm); $B$ - experimental setup for the DMW with $\mathrm{CO}_{2}$ cooling and mechanical restraints.

\section{$\mathrm{CO}_{2}$ Cooling Welding}

Experiments were carried out with single-pass, autogenous GTA butt joint welding of 1018 steel to 304 stainless steel. Dimensions of the plates were $300 \times 300 \times 3 \mathrm{~mm}-$ Fig. 3A. Compositions of these alloys are shown in Table 1. The welding parameters (displayed in Table 2) were designed so as to produce partial penetration, because no auxiliary argon gas was accommodated for weld protection underneath. After welding, the specimens were allowed to cool for 2000 s. This time allows the weldments to cool completely to ambient temperature before being released from the fixture. The active cooling source consisted of a $\mathrm{CO}_{2}$ snow jet that followed the welding torch at a distance of $40 \mathrm{~mm}$ with the same velocity - Fig. 3B.

In this research, there is a modest amount of practical development on the $\mathrm{CO}_{2}$ cooling method. The nozzle and power of the cooling source were not varied in the present study. In addition, the cooling source properties were not perfectly constant for all welds because the setup was a home-made apparatus. Consequently, there can be some variations in cooling between the different $\mathrm{CO}_{2}$ weldments. The main goal of this research was not to develop an ideal $\mathrm{CO}_{2}$ cooling setup, but to prove its effectiveness in reducing tensile $\mathrm{RS}$ in DMWs.

\section{Temperature Measurements}

Temperatures were recorded during the GTAW process using K-type thermocouples that were spot welded to the upper surface of the plates. An array of three thermocouples $(\mathrm{T} / \mathrm{C})$ was applied on a line perpendicular to the weld zone, with distances of 30,40 , and $50 \mathrm{~mm}$ away from the weld centerline. Measurements were taken during both conventional and $\mathrm{CO}_{2}$ welding processes.

\section{Stress Measurement Using the Neutron Diffraction Method}

In this study, the ND method was used to nondestructively measure the residual elastic stresses in the weldments (Ref. 12). These measurements were performed using the High Flux Isotope Reactor at Oak Ridge National Laboratory's (ORNL) $2^{\text {nd }}$ Generation Neutron Residual Stress Facility (Ref. 16). At each measurement point, lattice strains were calculated from the corresponding measured $d$-spacing changes in three orthogonal directions. Then the stress fields were calculated from the strain values. Full details of this measurement are given elsewhere (Ref. 12).

Table 1 - Chemical Composition of Steel Plates (wt-\%)

\begin{tabular}{|c|c|c|c|c|c|c|c|c|c|c|}
\hline Composition & C & $\mathrm{Mn}$ & $\mathrm{Si}$ & $\mathrm{P}$ & $S$ & $\mathrm{Cr}$ & $\mathrm{Ni}$ & Balance & $\mathrm{Ni}_{\text {eq }}$ & $\mathrm{Cr}_{\mathrm{eq}}$ \\
\hline $\begin{array}{l}1018 \text { steel } \\
\text { (average) }\end{array}$ & $0.13-0.20$ & $0.30-0.90$ & $0.15-0.30$ & $0-0.04$ & $0-0.05$ & - & - & $\mathrm{Fe}$ & $\approx 6$ & 0.3 \\
\hline $\begin{array}{l}304 \text { stainless } \\
\text { (average) }\end{array}$ & $0-0.08$ & 1.7 & 0.52 & $0-0.045$ & $0-0.035$ & 18.9 & 7.5 & $\mathrm{Fe}$ & $\approx 10$ & $\approx 20$ \\
\hline $\begin{array}{c}1018-304 \\
\text { WZ } \\
(E D A X)\end{array}$ & - & 1.14 & 0.12 & - & - & 7.58 & 4.32 & $\mathrm{Fe}$ & $\approx 7$ & $\approx 8$ \\
\hline
\end{tabular}



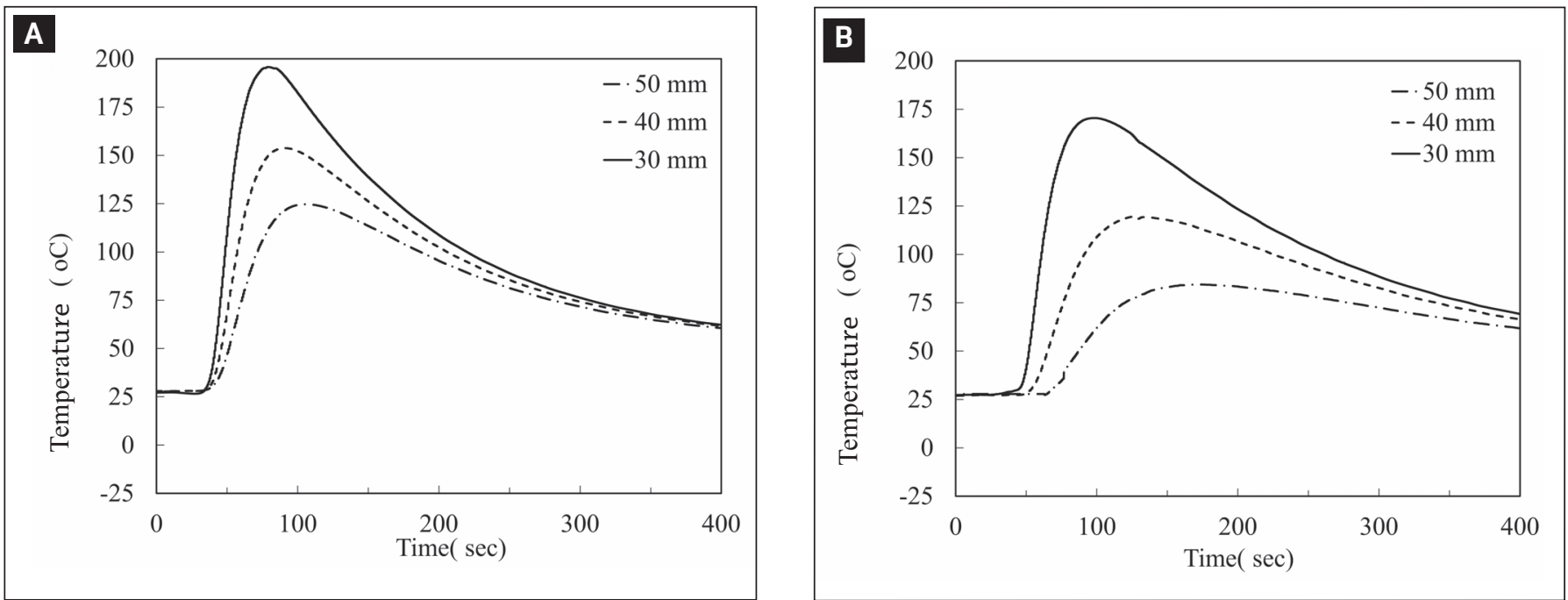

Fig. 4 - Temperature measurement in conventional GTA DMW: A - 1018 side; $\mathrm{B}-304$ side.
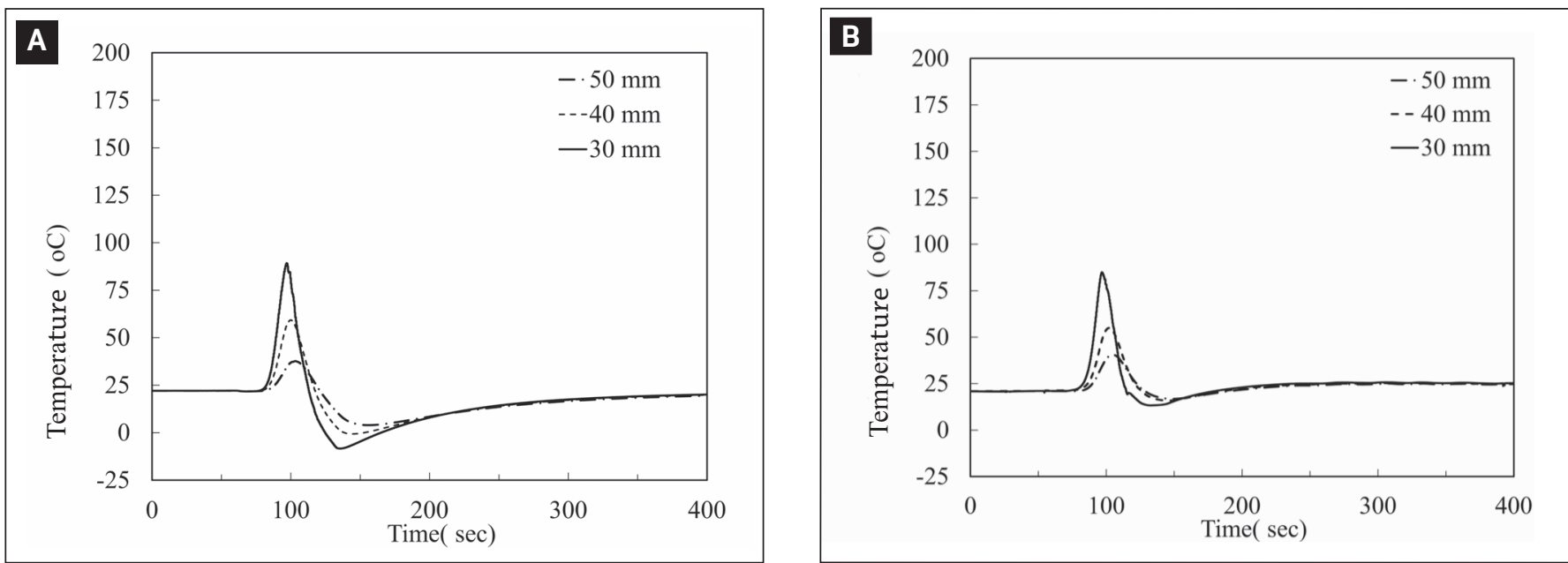

Fig. 5 - Temperature measurement in $\mathrm{CO}_{2}$ GTA DMW: $\mathrm{A}-1018$ side; $\mathrm{B}-304$ side.

\section{Microstructure Study}

It is important to analyze the microstructure of the weldments due to the increased cooling rate taking place using the $\mathrm{CO}_{2}$ cooling method. Optical microscopy and microhardness mesurements were used to identify the possible phases present in the weldments.

\section{Results and Discussions}

Figures 4 and 5 present temperature measurements of conventional and $\mathrm{CO}_{2}$ welding processes, respectively. These results show that the $\mathrm{CO}_{2}$ cooling was robust enough to sig- nificantly drop temperatures on both sides of the DMW even at locations 30,40 , and $50 \mathrm{~mm}$ away from the weld centerline. Figure 5 shows that the temperature drop in the 1018 side is larger than that of the 304 side. This is because the thermal conductivity of 1018 steel is greater than that of 304 . Hence, heating/cooling dissipation is faster in the 1018 weldment when compared to the 304 weldment.

\section{Effect of the $\mathrm{CO}_{2}$ Rapid Cooling Technique on Weld Distortion}

Welding of thin base metals (BM) with low stiffness generally produces distortions due to formation of residual

Table 2 - GTAW (DCEN) Parameters Used in This Study

\begin{tabular}{ccccc}
$\begin{array}{c}\text { Arc Voltage } \\
\text { (V) }\end{array}$ & $\begin{array}{c}\text { Arc Current } \\
(\mathrm{A})\end{array}$ & $\begin{array}{c}\text { Electrode Diameter } \\
(\mathrm{mm})\end{array}$ & $\begin{array}{c}\text { Arc Length } \\
(\mathrm{mm})\end{array}$ & $\begin{array}{c}\text { Travel Speed } \\
(\mathrm{mm} / \mathrm{s})\end{array}$ \\
\hline 18 & 150 & 2.4 & 1.5 & 4 \\
\hline
\end{tabular}




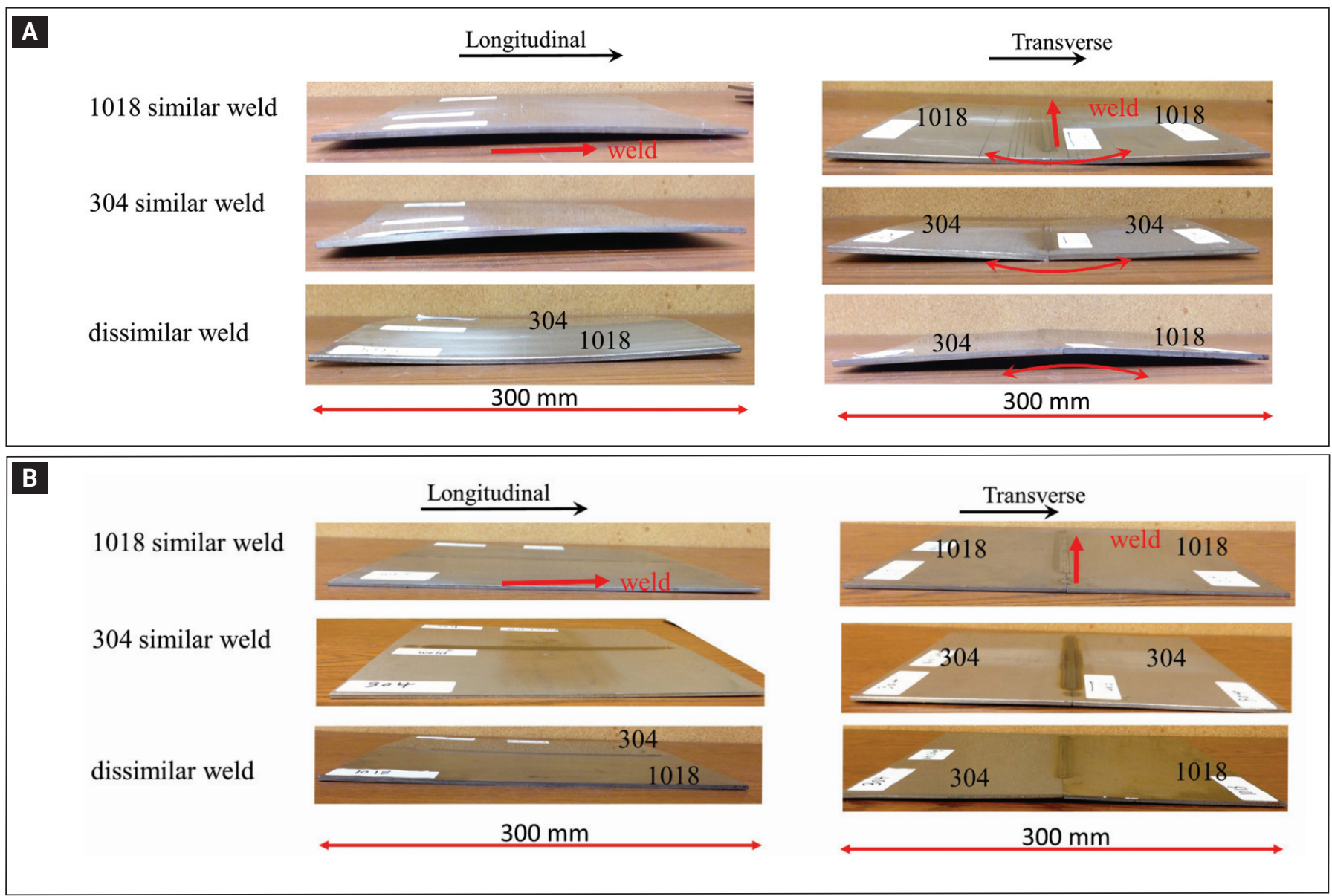

Fig. 6-Distortion observed in similar and dissimilar metal welds; $\mathrm{A}-$ Conventional weld; $\mathrm{B}-\mathrm{CO}_{2}$ weld.

plastic strains around weldments (Ref. 13). Different degrees of distortion can occur depending on the gradient forces/moments caused by longitudinal and transverse shrinkages (Ref. 14). In this section, curvatures, measured along the longitudinal and transverse edges with a dial gauge (see Fig. 3A), are addressed for both the conventional and $\mathrm{CO}_{2}$ weldments.

Figure 6 depicts distorted weldments for conventional and $\mathrm{CO}_{2}$ cooling along the longitudinal and transverse directions. As shown in Fig. 6A, a large distortion can be observed in the conventional welding process of all three weld cases, namely 1018-1018 similar, 304-304 similar, and 3041018 dissimilar weldments. Distortions in both directions (longitudinal and transverse) are large. However, these large distortions almost disappeared in the $\mathrm{CO}_{2}$-cooled weldments for all three cases - Fig. 6B.

Figure 7 shows the measured values of distortion in longitudinal (Fig. 7A) and transverse (Fig. 7B) directions with and without $\mathrm{CO}_{2}$ cooling for the similar and dissimilar weldments. From Fig. $7 \mathrm{~A}$ and $\mathrm{B}$, it can be concluded that $\mathrm{CO}_{2}$ cooling reduces the amount of distortion in 304-1018 DMWs from 3.5 to $0.5 \mathrm{~mm}$ for both longitudinal and transverse directions. It is worth noting that if excessive cooling power is used in this technique, it may reverse the direction of distortion. With the employment of the $\mathrm{CO}_{2}$ cooling technique, a large positive curvature in the longitudinal direction and a negative curvature in the transverse direction, which are a result of volume expan- sion due to the formation of martensite in the 1018-304 WZ (Ref. 12), were minimized.

\section{Weld Microstructure}

Figures 8 through 9 show microstructures of the WZ and $\mathrm{HAZ}$ in both conventional and $\mathrm{CO}_{2}$ weldments. The $\mathrm{BM}$ of the 1018 conventional weldment has microstructures of mainly ferrite and some pearlite; the HAZ contains fine pearlites due to the faster cooling rate, while the WZ contains coarse ferrite/pearlite as a result of the intermediate cooling rate - Fig. 8A and C. As depicted in Fig. 8B and D, the microstructure of the $\mathrm{HAZ}$ and WZ in the $1018 \mathrm{CO}_{2}$ weldment did not change to a degree where the difference between conventional and $\mathrm{CO}_{2}$ welds was noticeable. Figure $9 \mathrm{~A}$ and $\mathrm{C}$ show the microstructure of the conventional 304 weldment. It is well known that the microstructure of 304 is mainly composed of single-phase austenite. It shows a columnar dendritic structure within the WZ. Figure 9B and $\mathrm{D}$ show that by implementing $\mathrm{CO}_{2}$ rapid cooling during the welding process, the microstructure of the 304 similar weldment was not significantly influenced.

Figures 10 and 11 show the microstructure of the 3041018 weldment in conventional and $\mathrm{CO}_{2}$ rapid cooling conditions, respectively. According to the Schaeffler diagram (Ref. 12), the WZ of the 1018-304 weldment is martensitic. Similarly, it predicts that the WZ microstructure of the 


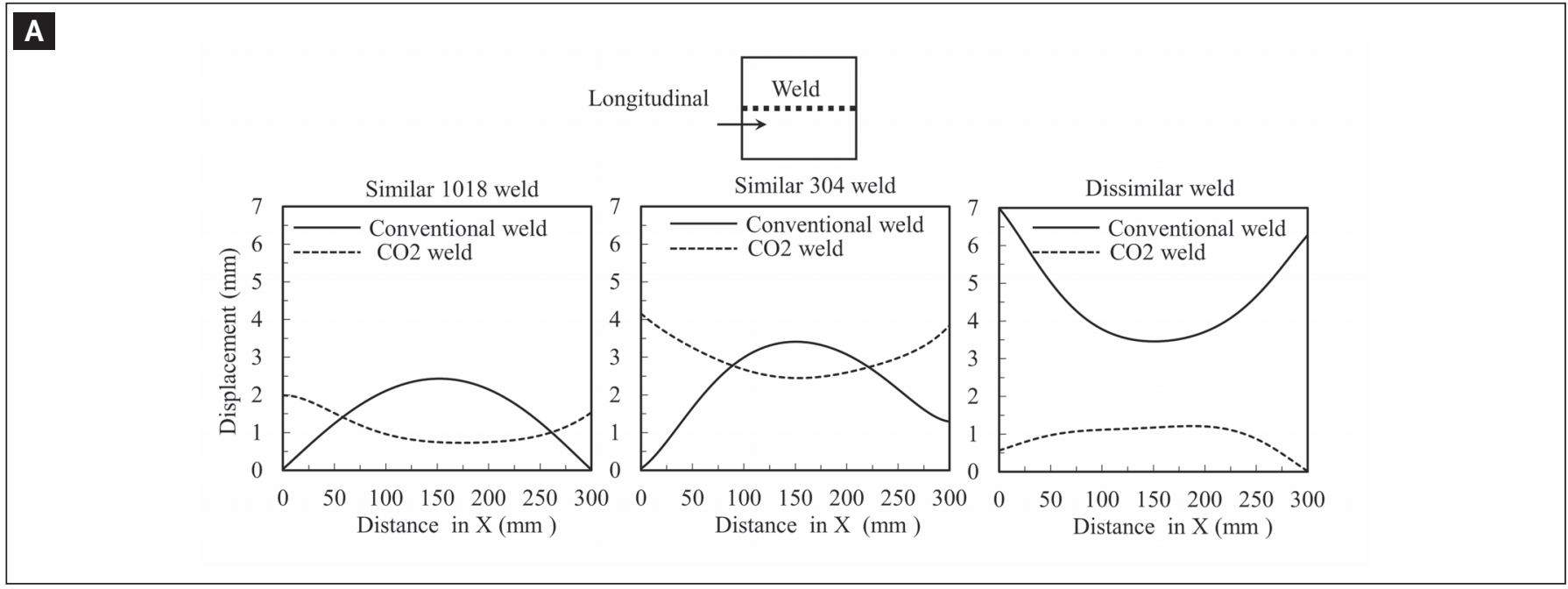

B

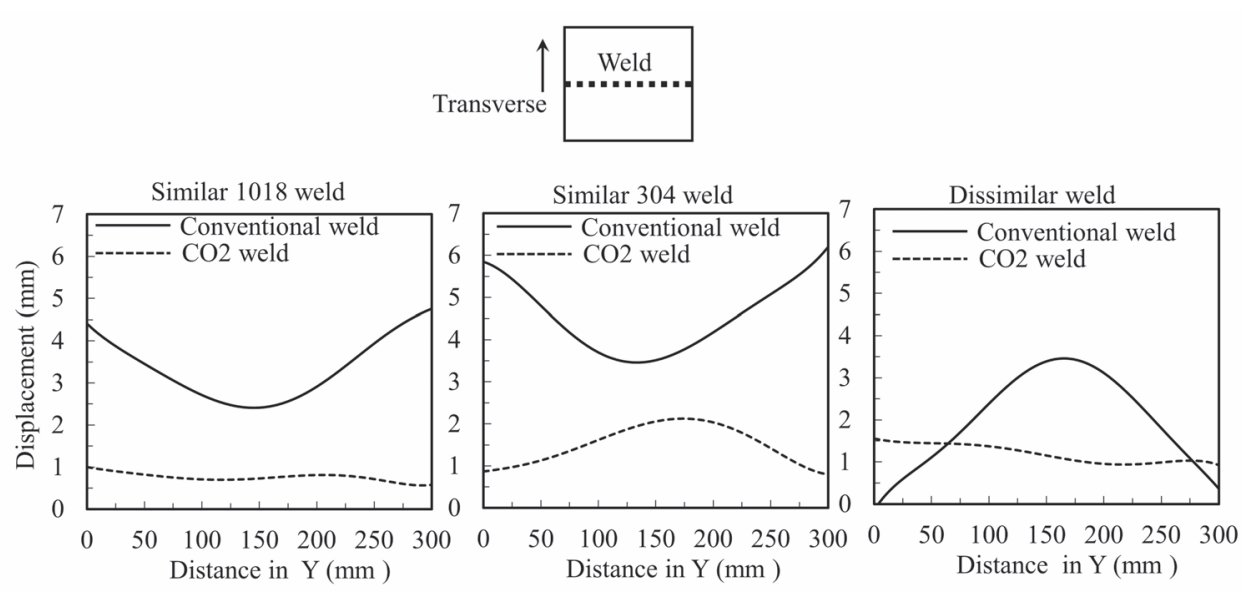

Fig. 7-Measured distortion in similar and dissimilar metal welds with and without $\mathrm{CO}_{2}$ cooling: A - Longitudinal; B - transverse.

1018-304 weldment made by the $\mathrm{CO}_{2}$ rapid cooling method is also martensitic.

\section{Microhardness Evaluation}

Hardness profiles can assist the interpretation of weld microstructure changes affected by the $\mathrm{CO}_{2}$ cooling technique. Microhardness tests were performed by measuring values across the weld cross section, crossing both the HAZ and WZ for the three cases (1018-1018, 304-304, and 1018304 weldments). The Vickers test was done with a load of $500 \mathrm{gf}$ and a loading time of $10 \mathrm{~s}$. Microhardness profiles across the six weldments are shown in Fig. 12.

Figure 12A shows that the hardness of the similar 1018 weldments made by the conventional and $\mathrm{CO}_{2}$ rapid cooling methods slightly increased from BM to HAZ to WZ. This is due to the increase in density of the fine ferrite phase. Hardness in the 304 weldments (Fig. 12B) made by the conventional and $\mathrm{CO}_{2}$ rapid cooling technique showed very similar values across both weldments. However, in the case of the 304-1018 weldments (Fig. 12C), a sharp increase in hardness (about $200 \mathrm{HV}$ ) was seen from the HAZ to the WZ. The reason behind this increase is the formation of martensite in the WZ, which confirms the microstructure predicted by the Schaeffler diagram. Implementation of $\mathrm{CO}_{2}$ rapid cooling did not significantly influence the hardness magnitude/distribution in the 1018 and 304 similar weldments. However, it did affect the hardness of the 1018-304 weldment. No visible cracks were observed in all the welds subjected to the $\mathrm{CO}_{2}$ rapid cooling process.

\section{Residual Stresses}

The main purpose of using the DC-LSND technique, such as the $\mathrm{CO}_{2}$ rapid cooling process, is to reduce $\mathrm{RS}$ during the welding process. The RS distribution for both the conventional and $\mathrm{CO}_{2}$ cooling weldments, measured using the ND technique, are shown in Figs. 13 to 16. It is important to note that the accuracy of strain measurements by the ND method is on the order of $\pm 50 \mu$, resulting in a RS resolution of $\pm 10 \sim 15 \mathrm{MPa}$.

According to Fig. 13A, the maximum longitudinal stress of 300 and $350 \mathrm{MPa}$ occurs in the WZ and the HAZ of the 304-304 weldment, respectively, which then decreases sharply with the increasing distance from the weld centerline. In the case of the 304-304 $\mathrm{CO}_{2}$ weldment (Fig. 13B), 

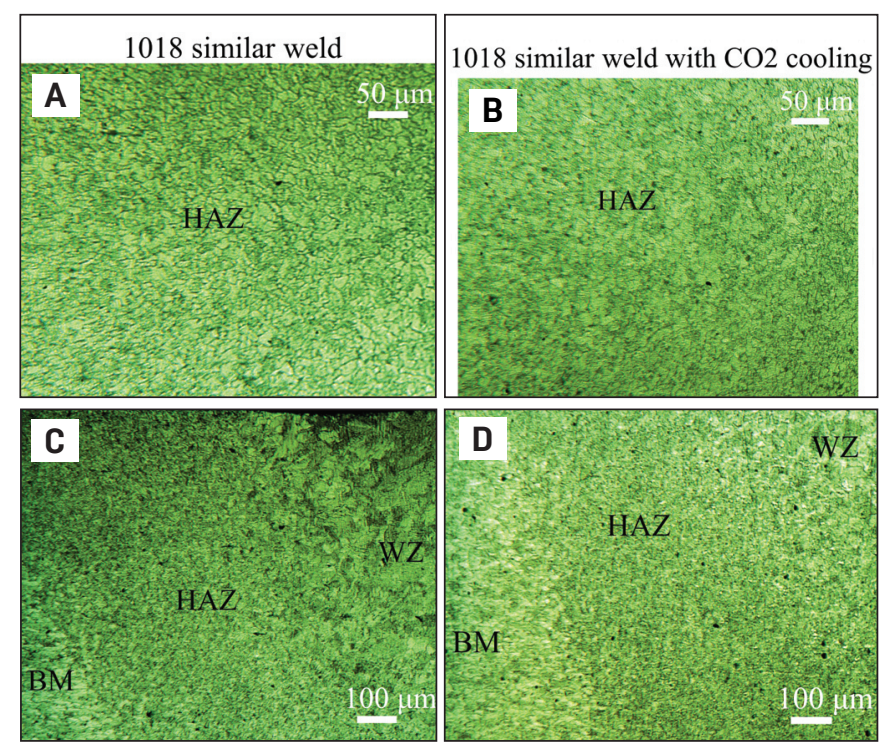

Fig. 8 - Microstructure of conventional 1018 weldments, etchant $2 \%$ nital.

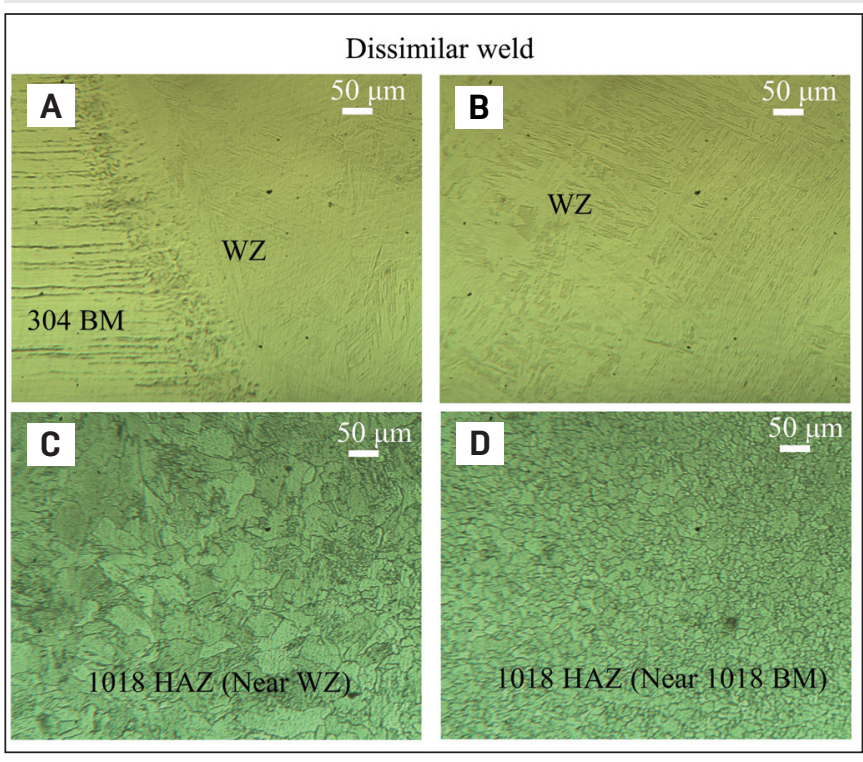

Fig. 10 - Microstructure of the conventional dissimilar weld, etchants $2 \%$ nital and $87 \%$ glyceregia.

the maximum longitudinal stress drops to $100 \mathrm{MPa}$ in the WZ. The asymmetric RS distribution across the 304-304 $\mathrm{CO}_{2}$ weldment is attributed to asymmetrical cooling due to misalignment of the $\mathrm{CO}_{2}$ nozzle.

Figure 14 shows the distribution of RS across the 10181018 conventional weldment (Fig. 14A) versus the 1018$1018 \mathrm{CO}_{2}$ weldment (Fig. 14B). In this case, the maximum longitudinal RS drops from 400 to $200 \mathrm{MPa}$ in the WZ by the $\mathrm{CO}_{2}$ cooling technique. Also, a 100-MPa RS reduction was observed in the transverse and normal directions for the $1018 \mathrm{CO}_{2}$ weldment. These results confirm the effectiveness of the $\mathrm{CO}_{2}$ rapid cooling process for the 1018 similar weldments.

The magnitude of longitudinal RS in the 1018 similar weld is larger compared to that of the 304 similar weld. Also, the RS evens out with a smaller gradient in the 1018 similar
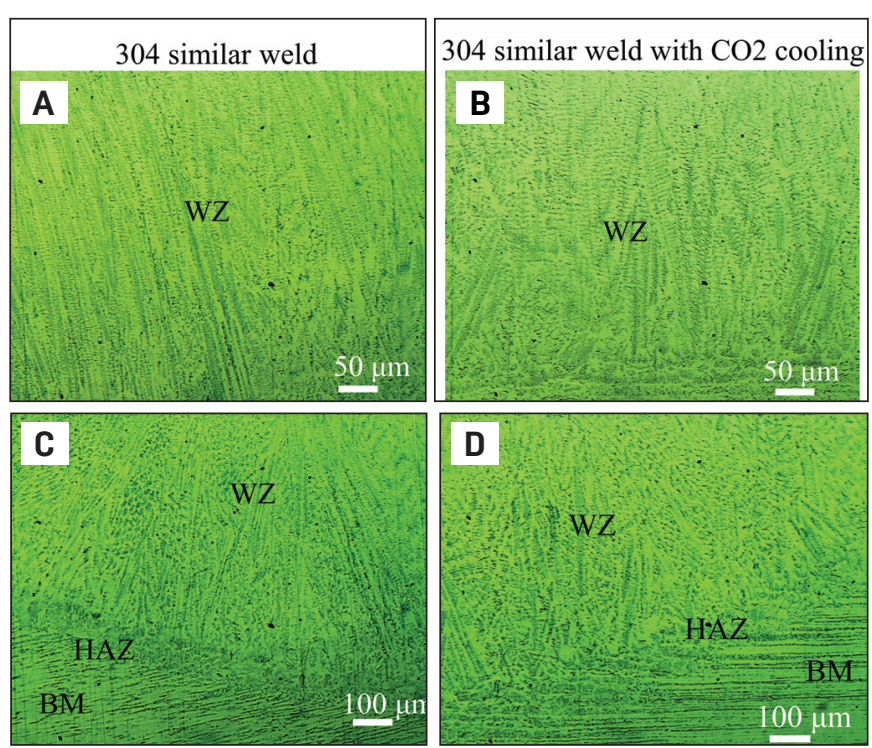

Fig. 9-Microstructure of the conventional 304 similar weld (left) and 304 similar $\mathrm{CO}_{2}$ weld (right), etchant $87 \%$ glyceregia.

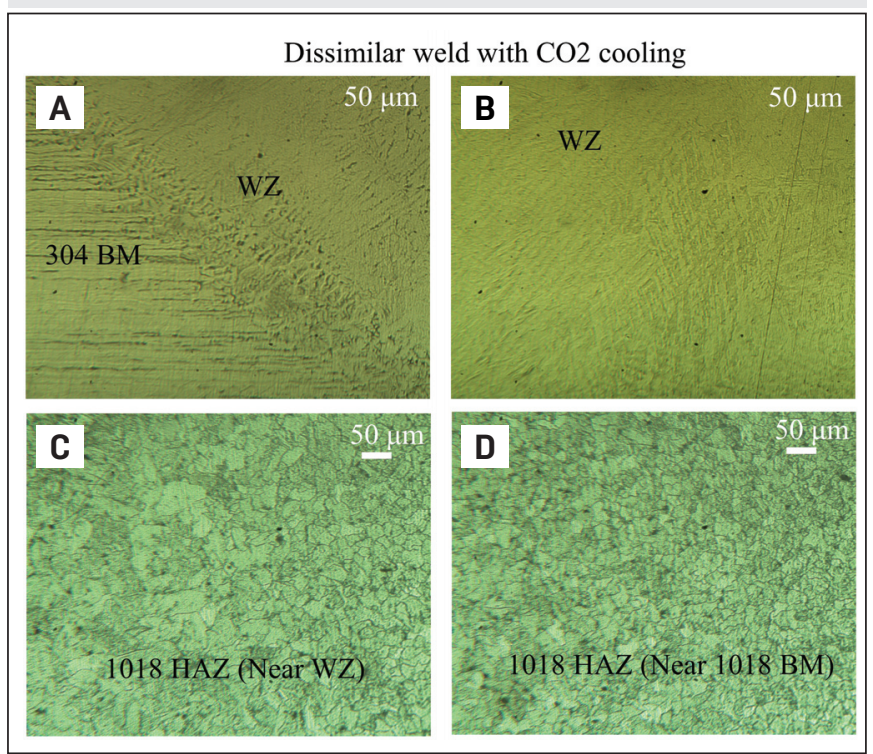

Fig. 11 - Microstructure of the $\mathrm{CO}_{2} \mathrm{DMW}$, etchants $2 \%$ nital and $87 \%$ glyceregia.

weld. The reason is that 1018 alloy has a lower coefficient of thermal expansion (CTE) and a larger yield strength (YS) compared to the 304 .

Generally, when a DMW is carried out, induced RS by the arc welding process could produce different RS distributions, especially near the WZ - Fig. 15A. This is due to the different CTE and YS of the base metals. Aside from material properties, the microstructure of the WZ in this DMW can contribute significantly to RS formation near the fusion boundary. It is shown that the microstructure of the WZ in the 304-1018 weldment is mainly martensitic because of the varied composition and rapid cooling (Ref. 15). When the face-centered cubic (FCC) structure of the WZ (austenite) transforms to the body-centered tetragonal (BCT) structure (martensite) during cooling, a volume expansion is experienced. This expansion produces a compressive stress within 
the WZ; however, it induces a tensile stress to the surrounding area outside of the WZ. It is interesting to note that the $\mathrm{RS}$ in the transverse direction undergoes a sharp increase near the WZ ( $\pm 5 \mathrm{~mm}$ ). The reason for this drastic change is again the existence of martensite at the top surface of the WZ (Ref. 15). The question then becomes the following: Why does experimental measurement show only tensile stress near the weld center? Given that the ND facility at ORNL measured only one phase on each side of the DMW (FCC on the 304 side and BCC on the 1018 side), the stress within the WZ, which is martensite (BCT), was not measured. It has been shown in previous numerical studies that the overall stress within the WZ of the 1018-304 DMW is mainly compressive (Refs. 12, 15).

Figure 15B shows RS distribution in the 304-1018 weldment exposed to the $\mathrm{CO}_{2}$ rapid cooling process. It shows that $\mathrm{RS}$ reduction took place effectively in the longitudinal and transverse directions, in which the RS dropped from 400 (Fig. 15A) to $250 \mathrm{MPa}$ (Fig. 15B) and from 300 (Fig. 15A) to $100 \mathrm{MPa}$ (Fig. 15B), respectively.

Several studies (Refs. 2, 7, 8) concentrated on the effectiveness of DC-LSND on RS distribution in the past two decades. With their experimental and numerical investigation, they successfully demonstrated that $\mathrm{CO}_{2}$ rapid cooling is capable of reducing RS significantly if proper parameters are used, such as distance between the cooling nozzle and the torch ( $\mathrm{arc}$ ), size of nozzle, and type of coolant. In this study, implementation of this technique on the 1018 similar weld can be another proof of principle.

In addition, the RS distribution of the 304 similar weld under the $\mathrm{CO}_{2}$ rapid cooling condition conveys the same belief, while neglecting the asymmetric behavior due to inconsistent experimental setup. Two common facts about all previous studies (Ref. 14) are that in-situ cooling was implemented on welded samples that were neither DMW nor subjected to undergo phase transformation. When similar metal welds (1018-1018 or 304-304 welds) are carried out under this rapid cooling condition, ideally the amount of RS reduced is constant through thickness (normal direction) if these welds do not undergo any phase transformation. Figure $16 \mathrm{~A}$ and $\mathrm{B}$ shows the schematics of the tensile and compressive stress distribution inside and outside of the WZ for

\section{A}

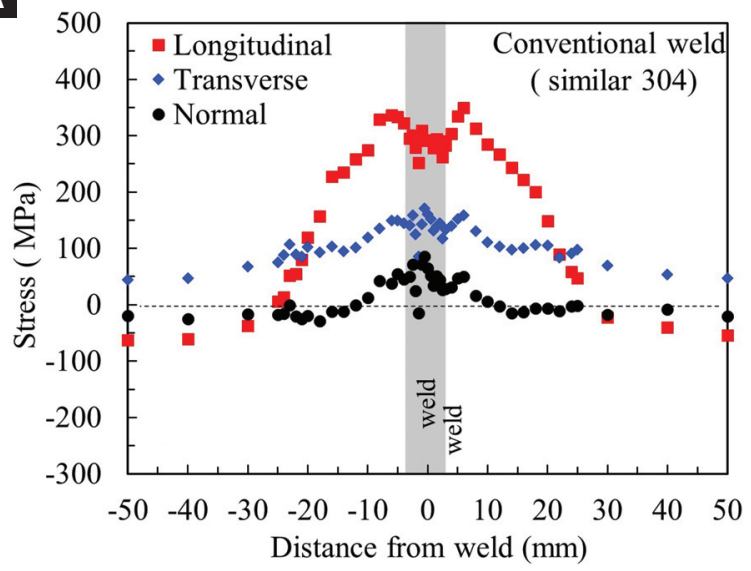

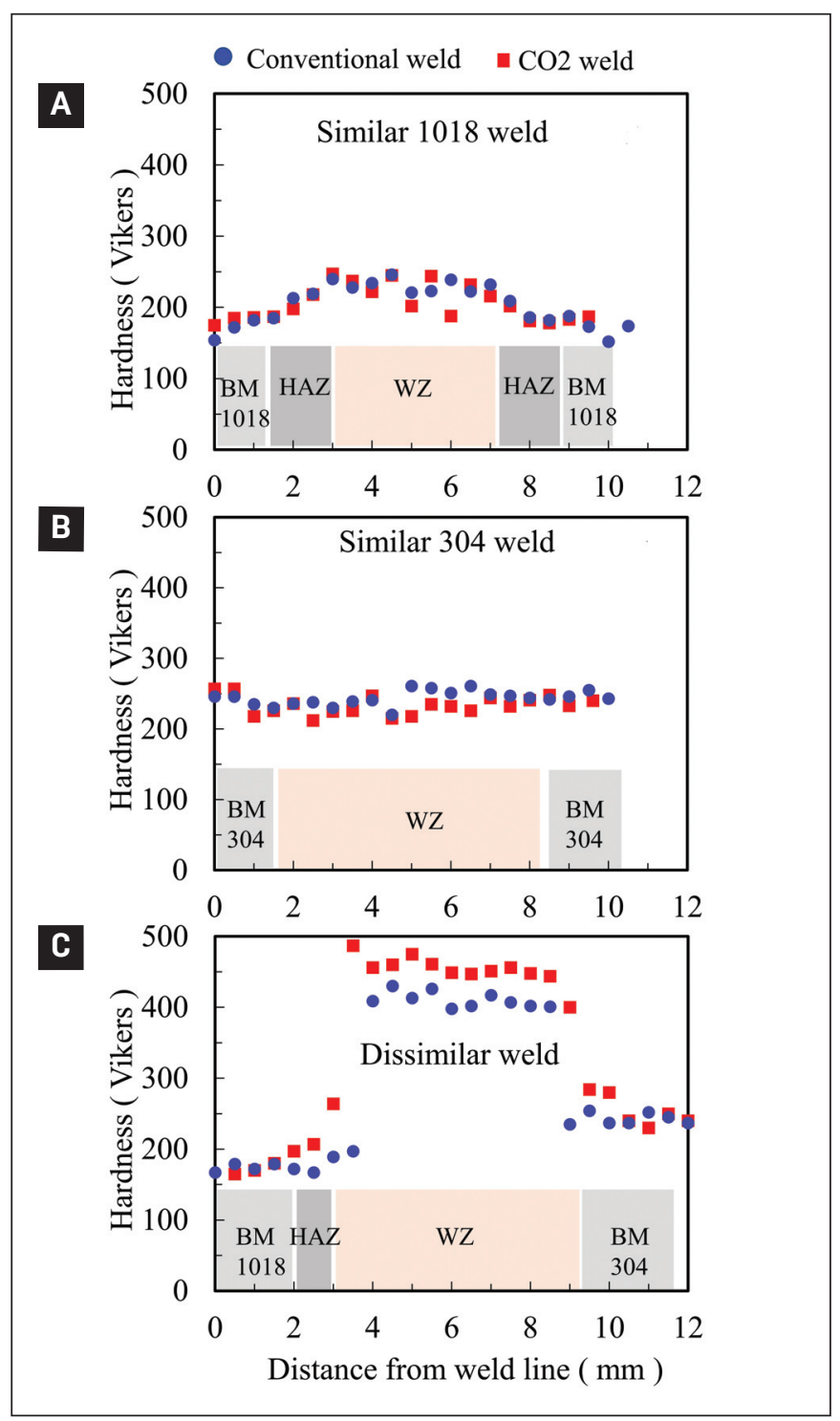

Fig. 12 - Microhardness profiles for welds made with and without the $\mathrm{CO}_{2}$ cooling method: blue circle - conventional weld; red rectangle $-\mathrm{CO}_{2}$-cooled weld.

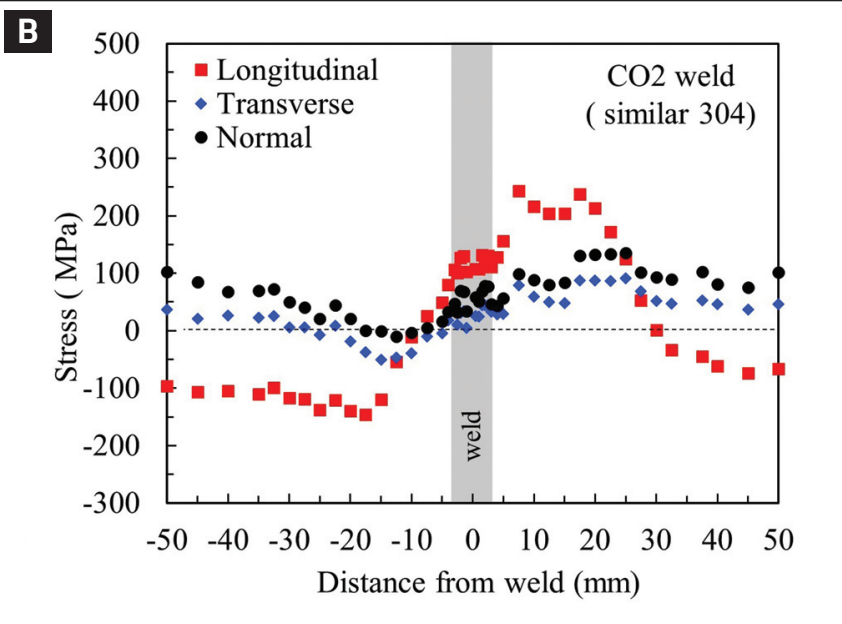

Fig. 13 - Longitudinal, transverse, and normal stress distributions in convectional 304-304 (left) and $304-304 \mathrm{CO}_{2}$ (right) weldments. 
A

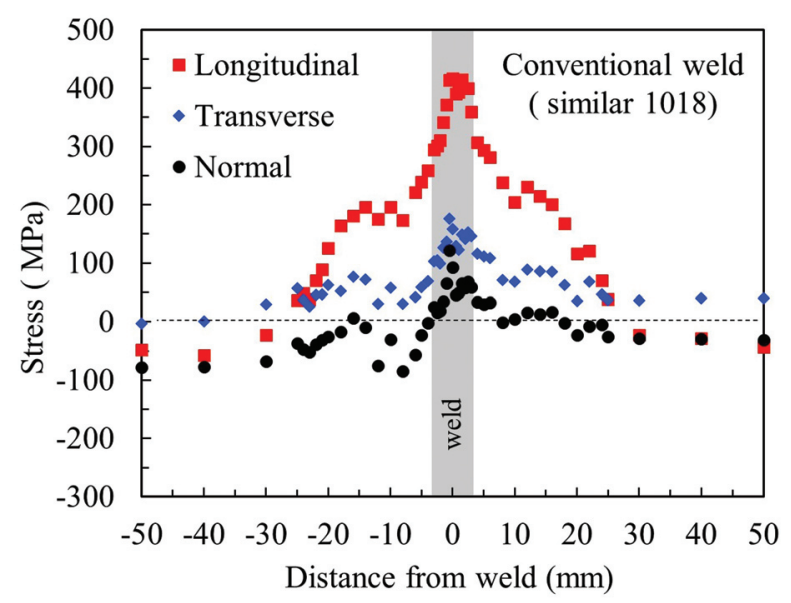

B

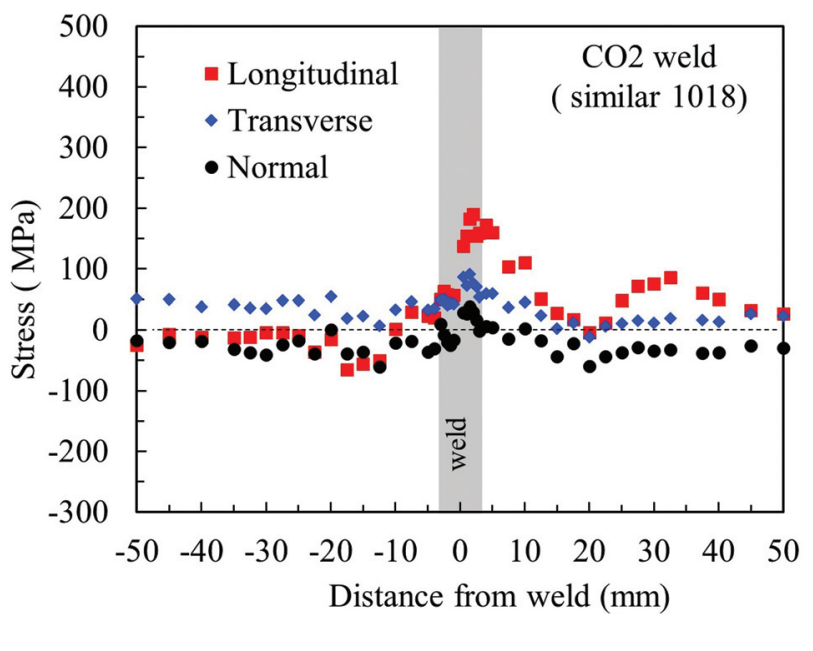

Fig. 14 - Longitudinal, transverse, and normal stress distributions in convectional 1018-1018 (left) and 1018-1018 $\mathrm{CO}_{2}$ (right) weldments.

A

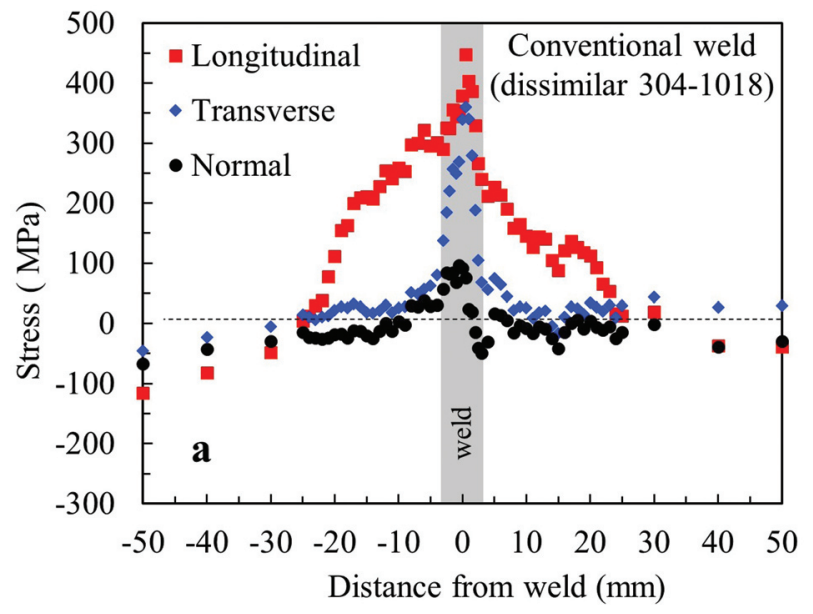

B

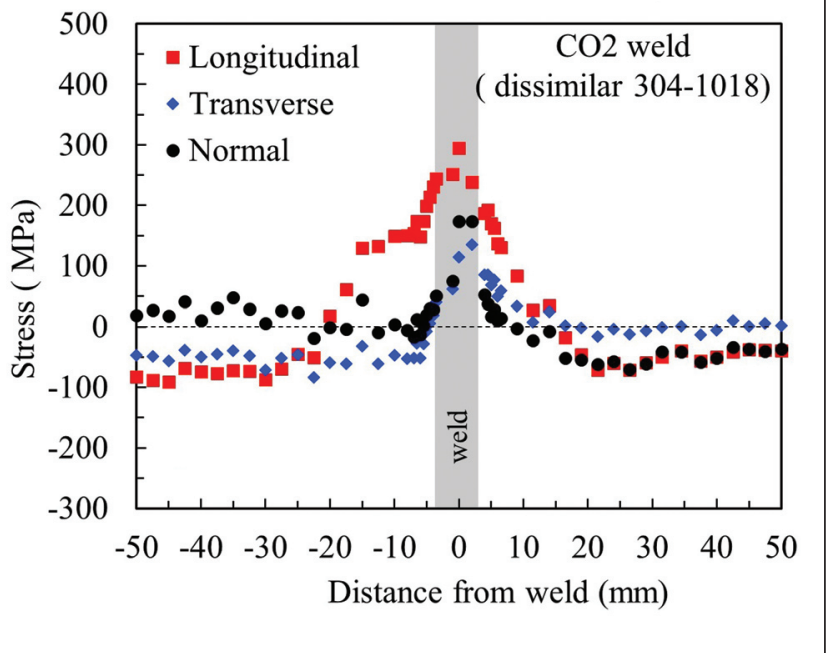

Fig. 15 - Longitudinal, transverse, and normal stress distributions in convectional (left) and $\mathrm{CO}_{2}$ cooling (right) of the $304-1018$ weld.

similar and dissimilar metal welds.

In this study, application of the $\mathrm{CO}_{2}$ rapid cooling technique was extended to 304-1018 DMWs, which have three phases: ferrite in the BM, and the HAZ on the 1018 side; austenite in the $\mathrm{BM}$, and the HAZ on the 304 side; and mainly martensite in the WZ. It is of interest to examine the interaction of these phases with $\mathrm{CO}_{2}$ cooling welds. Normally, in the WZ of conventional 304-1018 DMWs, martensite forms because of the varied composition and rapid cooling. The martensite formation induces compressive stress within the WZ, resulting in tensile stress to the surrounding area - Fig. 16C.

As shown in Fig. 16, dark arrows are a representation of RS formed purely due to heating and cooling during the welding process. However, the red arrows represent the stress due to formation of martensite. It is believed that under the rapid cooling condition, the magnitude of compressive/tensile stress due to formation of martensite does not change. All red arrows in Fig. 16C and D display the same magnitude of stress. However, the black arrows outside the WZ show that RS due to welding should drop with the implementation of rapid cooling. These hypotheses were confirmed by ND measurements - Figs. 13 and 15. According to these results, it can be concluded that the $\mathrm{CO}_{2}$ rapid cooling technique is not only effective on similar welds, but also effective on selected DMWs.

\section{Conclusions}

This study focused on the implementation of the $\mathrm{CO}_{2}$ rapid cooling technique on 1018 and 304 similar and 3041018 DMWs. For this purpose, a setup was designed at Clarkson University, Potsdam, N.Y., to make welds under controlled conditions.

The cooling source size and heat transfer coefficient could 


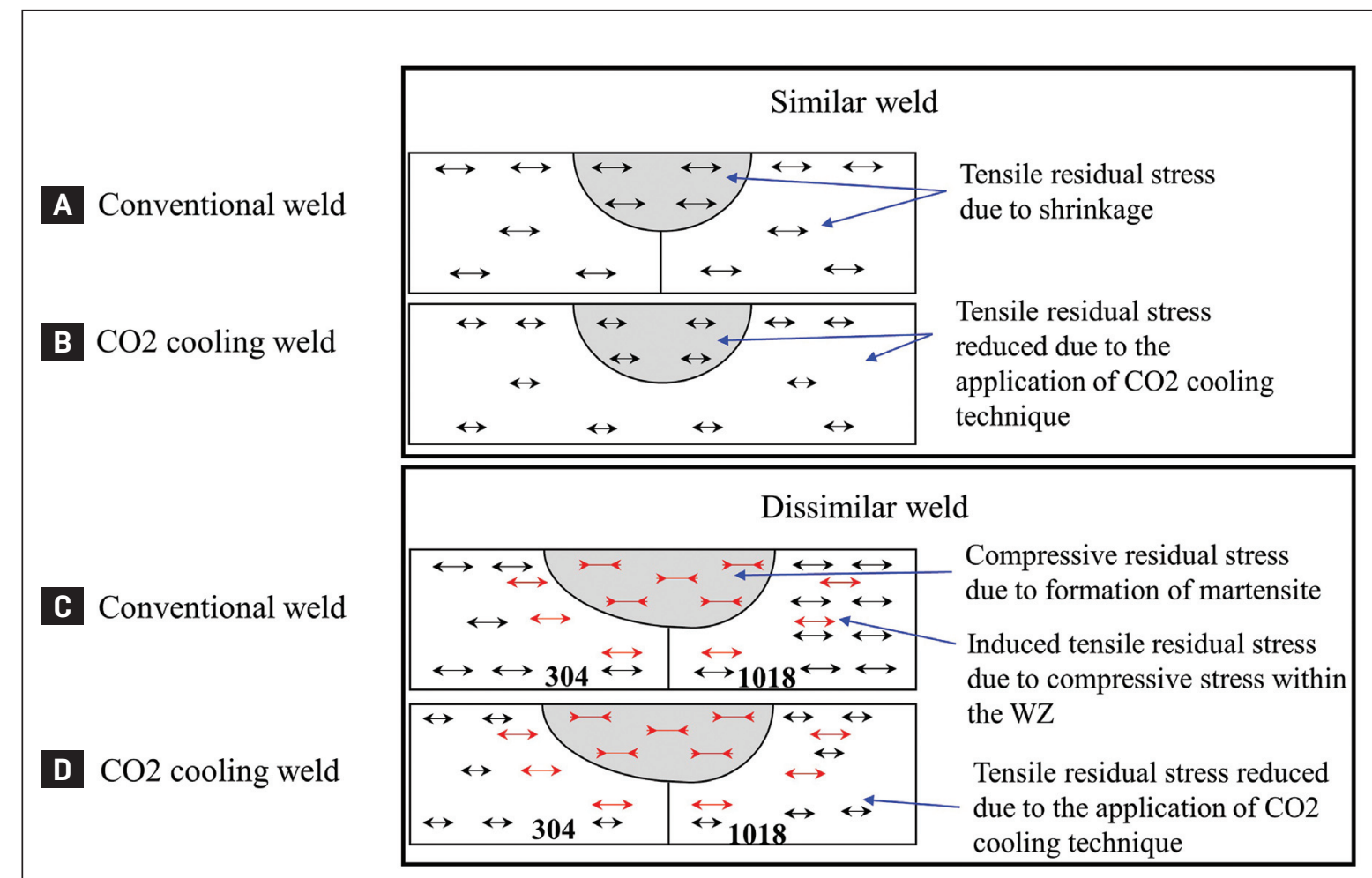

Fig. 16 - Longitudinal, transverse, and normal stress distributions in the conventional weld and $\mathrm{CO}_{2}$ DMW (304-1018 dissimilar): $\mathrm{A}-$ Conventional weld; $\mathrm{B}-\mathrm{CO}_{2}$ cooling weld; $\mathrm{C}-$ conventional weld; $\mathrm{D}-\mathrm{CO}_{2}$ cooling weld.

not be changed. Spraying dry ice $\mathrm{CO}_{2}$ during welding resulted in a drastic drop in temperature, localized at the cooling source position. During the conventional welding process of thin plates, the samples showed an out-of-plane deformation and severe buckling deformation. Distortion of 304 and 1018 similar and their DMW were measured and compared with their corresponding $\mathrm{CO}_{2}$ rapid cooled welds. It was experimentally shown that the $\mathrm{CO}_{2}$ rapid cooling welding process can be exceptionally successful in the elimination of buckling distortion in thin plates.

The influence of such active cooling was investigated on the microstructures of similar and DMW. In the 1018 and 304 similar welds, no significant influence of $\mathrm{CO}_{2}$ on the weld microstructure was found. However, this technique led to a modest increase in hardness in the DMWs.

The RS distributions of conventional and $\mathrm{CO}_{2}$-cooled weldments were investigated by ND technique. According to these results, it can be found that the $\mathrm{CO}_{2}$ cooling technique is not only effective on similar welds, but it is also successful on DMWs.

Improvement of the $\mathrm{CO}_{2}$ rapid cooling technique is important to deliver the desired hardness and microstructure in the DMWs.

\section{Acknowledgments}

This research used resources from the High Flux Isotope Reactor, a Department of Energy Office of Science user facility operated by the Oak Ridge National Laboratory, Oak Ridge, Tenn. The authors would like to thank John Goldak for his valuable suggestions.

\section{References}

1. Joseph, A., Rai, S. K., Jayakumar, T., and Murugan, N. 2005. Evaluation of residual stresses in dissimilar weld joints. Int. J. Press. Vessel. Pip. 82(9): 700-705. DOI: 10.1016/j.ijpvp.2005.03. 006

2. Li, J., Guan, Q., Shi, Y., Guo, D., Du, Y., and Sun, Y. 2004. Studies on characteristics of temperature field during GTAW with a trailing heat sink for titanium sheet. J. Mater. Process. Technol. 147(3): 328-335. DOI: 10.1016/j.jmatprotec.2003.12.012

3. Richards, D. G., Prangnell, P. B., Williams, S. W., and Withers, P. J. 2008. Global mechanical tensioning for the management of residual stresses in welds. Mater. Sci. Eng. A 489(1-2): 351-362. DOI: 10.1016/j.msea.2007.12.042

4. Price, D. A., Williams, S. W., Wescott, A., Harrison, C. J. C., Rezai, A., Steuwer, A., Peel, M., Staron, P., and Koçak, M. 2007. Distortion control in welding by mechanical tensioning. Sci. Technol. Weld. Join. 12(7): 620-633. DOI: 10.1179/174329307X213864

5. Guan, Q., Guo, D. L., Li, C. Q., and Leggatt, R. H. 1994. Low stress non-distortion (LSND) welding - A new technique for thin materials. Welding in the World 33: 160.

6. Li, J., Guan, Q., Shi, Y. W., and Guo, D. L. 2004. Stress and distortion mitigation technique for welding titanium alloy thin sheet. Sci. Technol. Weld. Join. 9(5): 451-458. DOI: 10.1179/ 136217104225021643

7. van der Aa, E. M., Hermans, M. J. M., Richardson, I. M., van der 
Pers, N. M., and Delhez, R. 2006. Experimental study of the influence of a trailing heat sink on the welding residual stress distribution. Mater. Sci. Forum. 524-525: 479-484. DOI: 10.4028/ www.scientific.net/MSF.524-525.479

8. Richards, D. G., Prangnell, P. B., Withers, P. J., Williams, S. W., Nagy, T., and Morgan, S. 2010. Efficacy of active cooling for controlling residual stresses in friction stir welds. Sci. Technol. Weld. Join. 15(5): 156-165. DOI: 10.1179/ 136217109X12590746472490

9. Richards, D. G., Prangnell, P. B., Withers, P. J., Williams, S. W., Nagy, T., and Morgan, S. 2008. Simulation of the effectiveness of dynamic cooling for controlling residual stresses in friction stir welds. $7^{\text {th }}$ Int. Symp. Frict. Stir Welding, TWI. DOI: 10.1179/ $136217109 X 12590746472490$.

10. Han, W. T., Wan, F. R., Li, G., Dong, C. L., and Tong, J. H. 2011. Effect of trailing heat sink on residual stresses and welding distortion in friction stir welding Al sheets. Sci. Technol. Weld. Join. 16(5): 453458. DOI: 10.1179/1362171811Y.0000000015

11. Luan, G., Li, G., Li, C., and Dong, C. 2008. DC-LSND friction stir welding, TWI. $7^{\text {th }}$ Int. Frict. Stir Weld. Symp. Osaka, Japan.

12. Eisazadeh, H., Bunn, J., Coules, H. E., Achuthan, A., Goldak, J., and Aidun, D. K. 2016. A residual stress study in similar and dissimilar welds. Welding Journal 95(4): 111-s to 119-s.

13. Soul, F. A., and Zhang, Y.-H. 2006. Numerical study on stress induced cambering distortion and its mitigation in welded titanium alloy sheet. Sci. Technol. Weld. Join. 11(6): 688-693. DOI:

10.1179/174329306X147715

14. Eisazadeh, H., and Aidun, D. K. 2017. Investigation of transient/residual strain and stress in dissimilar weld. J. Manuf. Process. 26: 372-381. DOI: http://dx.doi.org/10.1016/ j.jmapro. 2017.03.003

15. Eisazadeh, H., Bunn, J., and Aidun, D. K. 2017. Numerical and experimental investigation of residual stress distribution in a dissimilar ferritic austenitic weld. Welding Journal 96(1): 21-s to 30-s.

16. Cornwell, P., Bunn, J., Fancher, C. M., Payzant, E. A., and Hubbard, C. R. 2018. Current capabilitites of the residual stress diffractometer at the high flux isotope reactor. Review of Scientific Instruments 89(9): 92804. DOI: https://doi.org/10.1063/1.5037593
TITLE OF PUBLICATION: Welding Journal

DATE OF FILING: September 28, 2018

NO. OF ISSUES PUBLISHED ANNUALLY: 12

2. PUBLICATION NO.: ISSN 0043-2296

4. FREQUENCY OF ISSUE: Monthly

6. ANNUAL SUBSCRIPTION: $\$ 120.00$

MAILING ADDRESS OF KNOWN OFFICE OF PUBLICATION: 8669 NW 36 St., \#130, Miami, Florida 33166

MAILING ADDRESS OF THE HEADQUARTERS OR GENERAL BUSINESS OFFICES OF THE PUBLISHERS:

8669 NW 36 St., \#130, Miami, Florida 33166

NAMES AND COMPLETE ADDRESS OF PUBLISHER, EDITOR AND MANAGING EDITOR:

PUBLISHER: Mary Ruth Johnsen, AWS, 8669 NW 36 St., \#130, Miami, Florida 33166

EDITOR: Mary Ruth Johnsen, AWS, 8669 NW 36 St., \#130, Miami, Florida 33166

OWNER: $\quad$ NAME: American Welding Society, Inc. $\quad$ ADDRESS: AWS, 8669 NW 36 St., \#130, Miami, Florida 33166

KNOWN BONDHOLDERS, MORTGAGEES, AND OTHER SECURITY HOLDERS OWNING OR HOLDING 1 PERCENT OR MORE

OF TOTAL AMOUNT OF BONDS, MORTGAGES OR OTHER SECURITIES: None

The purpose, function, and nonprofit status of this organization and the exempt status for Federal income tax purposes:

Has not changed during preceding 12 months

Publication Title: Welding Journal

14. Issue date for Circulation Data Below: October 2018

15. EXTENT AND NATURE OF CIRCULATION:

A. Total No. Copies Printed (Net Press Run)

B. Paid and/or Requested Circulation

1. Paid / Requested Outside-County Mail Subscriptions Stated on Form 3541

2. Paid In-County Subscriptions Stated on Form 3541

3. Sales Through Dealers and Carriers,

Street Vendor, Counter Sales, and other Non-USPS Paid Distribution

4. Other Classes Mailed Through the USPS

C. Total Paid / Requested Circulation

D. Free Distribution by Mail (Samples, complimentary and other free)

1. Outside-County as State on Form 3541

2. In-County as Stated on Form 3541

3. Other Classes Mailed Through the USPS

4. Free Distribution Outside the Mail (Carriers or other means)

E. Total Free Distribution

F. Total Distribution

G. Copies not Distributed

H. Total

I. Percent Paid and / or Requested Circulation

16. Statement of Ownership will be printed in the November 2018 issue of this publication.

I certify that the statements made by above are correct and complete:

Mary Ruth Johnsen, Editor

$\begin{array}{rr}\text { Average No. Copies Each } & \text { Actual No.Cop } \\ \text { Issue During Preceding } & \text { Single Issue Pu } \\ 12 \text { Months } & \text { Nearest to Filin } \\ 51,716 & 54,100 \\ 49,584 & 50,458 \\ \text { None } & \text { None } \\ \text { None } & \text { None } \\ & \\ \text { None } & \text { None } \\ 49,584 & 50,458 \\ & \\ 149 & 149 \\ \text { None } & \text { None } \\ \text { None } & \text { None } \\ \text { None } & \text { None } \\ 149 & 149 \\ 49,733 & 50,607 \\ 1,983 & 3,493 \\ 51,716 & 54,100 \\ 99.7 \% & 99.7 \%\end{array}$

